\title{
The "Conversion" of Nursing by Jewish Orthodox Women in Israel
}

\author{
Raz Haya \\ Jerusalem College of Technology
}

\begin{abstract}
The Christianity influence in nursing until the 19th century made nursing an uncommon profession among Jewish religious communities mostly in Europe. In the early stages of the development of the state of Israel, a need for nurses led religious Jewish women to join the profession, first in Jewish religious hospitals and then in other hospitals too. The goal of this study was to describe Jewish Orthodox women's approach to the nursing profession, integrating the values of Judaism and nursing. This study is based on a literature review, official documents, and semistructured personal interviews, conducted with 10 veteran religious nurses in Israel. This study describes Jewish Orthodox women's willingness and affords in the early years of Israel's founding to cope with the unique challenges that nursing presented, constituted a breakthrough for many nurses today. We demonstrate that nursing is a profession of caring for others; all cultures and religious can contribute to and benefit from.
\end{abstract}

Keywords: Jewish Orthodox nursing, religious nurses, nursing in Israel

The religious Jewish female nurse and her unique characteristics had to integrate the values of Judaism and nursing that had developed mainly under the influence of Christianity. The nursing academic school for religious Jewish women established in the Tal Institute of The Jerusalem College of Technology-Lev Academic Center (2006) was the first of its kind in Israel. In this study, we describe the process of the unique characteristics of the religious Jewish nursing according to official documents, relevant literature, and semistructured interviews with veteran religious nurses and/or nurses working in health institutes affiliated with the religious Jewish community. The nurses interviewed were among the first nurses in Israel to come from the Orthodox Jewish community. The goal of the study was to describe the successful process of nursing profession among Orthodox Jewish women, emphasizing the unique challenge of adhering not only to professional values, but also to the values and tenets of Orthodox Judaism.

Primary sources for this project came from documents and archives from the first Jewish religion nursing schools and hospitals, and personal diaries of the nurses working there. Utilizing a social history approach, we paid particular attention to the experiences of first Jewish Orthodox nurses. We attempt to understand their experiences and motivation to cope with being professional nurses while leading a Jewish Orthodox way of life. We contacted ten Jewish Orthodox female nurses, potential interviewees that were eagerly willing to tell their story. Most of these nurses were veteran nurses who were among the first generation to establish the profession

Raz Haya, RN, Ph.D., Faculty for Life Sciences and Health, Nursing School, Tal Campus, Jerusalem College of Technology, Israel; main research field: Nursing and Childhood Cancer.

Acknowledgment: Applebaum Hodaya, Ben Atar Rivka, Goldner Ayelet, Dvir Meital, Meshbaum Chagit, Sukhi Rachel, Orkavi Chen, Kirshenbaum Tamar, and Rubinstein Rachel. 
in Israel. They completed their professional studies between the years of 1960 and 1980. All of the interviewees had held an administrative position in their place of work.

\section{The Religious Jewish Female Nurse as Described in the Literature and Official Documents}

In Judaism, Midwives are the first type of nurse mentioned in the Bible. They are mentioned nine times, always in the feminine form of the noun. The Bible clearly delineates midwifery as a female profession, which aims to facilitate in the delivery of new life and provide care for both mother and newborn. Specifically, midwives are mentioned in the Book of Bereshit (Genesis): in Rachel's delivery of Benjamin $(35,17)$ and in the delivery of Tamar's twins, Peretz and Zerach. The book of Shmot (Exodus) relates the story of two brave and brazen midwives, Shifra and Pu'a, who defied the Pharaoh's command to murder all male Jewish newborns $(1,15-21)$. In other Scriptures, the role of the midwife is suggested indirectly.

In documentation prior to the 19th century, religious Christian men and women are described as nurses. They were portrayed as dedicated to serving the ill, administering to the dying, and assisting in surgical and other medical procedures. In Europe, before the Modern era, Jewish midwives served in medical roles and as community caregivers. They also had an important function related to issues of ethics and morality, as they were involved in the family life and private lives of every individual in their communities. The historian Wasner claimed that midwifery was the most important profession that a woman could choose in that era. Midwives attended to medical needs in their communities, intervened in cases of marital disputes (e.g., infidelity and incest), and had the power and authority on these issues, regardless of whether the people involved were all Jewish, or the issues at hand pertained to relationships between Jews and non-Jews.

According to the literature, in Yemen, between 1931 and 1949, there were almost no official health services in general, or for the Jewish community in particular. As a result, the profession of Jewish midwifery developed and was passed from one generation to the next, based on religious Scripture, oral traditions, and practical knowledge.

Before World War I, Jewish communities in Poland had their own Jewish hospitals that employed Jewish nurses, although the nurses had received no official training, but rather had acquired the necessary skills on the job. After World War I, seven nursing schools were established in Poland; however, one of the conditions for entering the program was to have been properly baptized according to the church. Consequently, Jewish women could not attend these nursing schools and therefore special Jewish nursing schools were established. According to the documentation by nurse Selma, and the Women's Zionist Organization of America, in some countries in Europe and in the United States during the 19th century, religious Jewish women were able to attend official nursing schools.

\section{Nurses in Israel before 1948}

Until 1918, while the Land of Israel was under the Ottoman rule, nurses were not required to study before entering the profession. Rather, the term nurse was applied to anyone who provided care to the ill or served as a physician's assistant. At the end of the 19th century and into the early 20th century, attendees in Jewish hospitals were men whose only education consisted of reading and writing, and women whose work was considered "even in the lowest rung," because of their ignorance. "During the Ottoman rule, a woman working as a nurse was considered to have lost her way in life.” In 1918, the first nursing school was established in 
Jerusalem, initiated by the Hadassah Women's Zionist Organization of America. Until 1936, registered nurses in Israel were either graduates of nursing schools established in Israel or they had been educated abroad. Given the ever-increasing need for more nurses in the Israeli workforce, additional nursing schools were founded, such as those affiliated with the Hospitals of Beilinson and Shaarei Tzedek.

The Unique Challenges Faced by Religious Jewish Women Nurses: In this section, we present the unique challenges with which religious Jewish women nurses must contend, based on findings from the literature and from the interviews. The dilemmas that the religious Jewish nurse faces stem from the need to abide by the professional requirements, while simultaneously maintaining a religious way of life, according to the Jewish tenets.

\section{Observing the Sabbath}

The Shabbat laws are quite complex and there are some activities from which Jewes are refrained on Shabbat. For better understanding the challenges of these women, we describe some of these activities that nurses have to do while treating patients: working, nwriting, erasing and tearing; driving or riding in cars or other vehicles; using the telephone or computer; turning on or off anything which uses electricity etc.

Jewish ritual laws pertaining to the nurse's need to work on the Sabbath were found in a book written on this specific topic by Rabbi Noibert in 1976, and in the book titled The Soul of Abraham. According to the Shulchan Aruch (a book considered the "Code of Jewish Law" written by Rabbi Yosef Karo in 1563), in the section titled Orach Chayim (Way of Life) subsection 328 (on treating the sick on the Sabbath), paragraph 2, it states the following: "it is a Mitzvah (an act of kindness) to desecrate the Sabbath in order to help a critically ill person; in fact, the sooner the better. To question this precept is tantamount to spilling the blood of another human being."

The remaining doubts in terms of the potential conflict between Jewish law (Halacha) and the demands of the nursing profession pertain to the performance of basic and routine activities, those which under normal circumstances are forbidden on the Sabbath. These activities include the operation of electric devices, writing, cutting open wrappings and packages, in this case, materials used to treat the sick. Hospitals affiliated with the Jewish Orthodox movement attempted to cope with such difficulties by employing non-Jewish workers during the Sabbath, whose role was to follow the nurses' instructions, to operate electric devices, and complete any actions which the religious Jewish nurse was not allowed to perform on the Sabbath. "We would use paperclips and then after the Sabbath we would complete the calculations... Before the Sabbath began, we would cut the bandages and adhesive bandages and cards/pieces of paper, etc.” (R. M.). Another interviewee noted:

At first, each individual nurse would consult her Rabbi about her own specific set of questions, until it became clear that we all needed a single central resource that would address all of the issues we encountered as religious Jewish nurses. All of these questions were sent to Rabbi Noibert, and then a weekly meeting was held to provide responses. (N. TZ.)

Traveling back and forth to the hospital on the Sabbath or on holidays was also an issue related to the potential desecration of the Sabbath. According to The Soul of Abraham, the Jewish nurse is allowed to travel on the Sabbath to the hospital in order to carry out her shift. If possible, it is better to have a non-Jewish driver; however, if a non-Jewish driver is not available, in this case even Jews are allowed to drive. Furthermore, for the particular purpose of attending a nurse's hospital shift, the nurse is not required to make an unusual effort to avoid traveling on the Sabbath, such as spending the Sabbath within walking distance to the hospital or at a place where a non-Jewish driver is available. In general, however, the permission to use a Jewish driver is the 
exception and should not be used as a rule. It is permitted to return home after the shift and during the Sabbath, but in this case, only with a non-Jewish driver in a commercial vehicle. "At first even this was not allowed; later permission was granted because there were so many nurses coming in from neighboring towns” (N. TZ.).

\section{The Prohibitions against Touching and Seclusion}

Jewish law prohibits any touching between a man and a woman who are not married to each other, as well as any situation that leaves a man and a woman who are not married to each other secluded in an isolated area. According to The Soul of Abraham, at first, it was considered inappropriate for a female nurse to catheterize a male patient, and vice versa. However, if there is no one else available to perform the procedure and the patient would suffer as a result-it is permitted. In the book, A Halachic Guide for Hospital Nurses, Noibert notes that even in the hospital it is important to abide by the prohibition against seclusion; hence, when a female nurse attends to a male patient or when a male doctor attends to a female patient, the door to the room must remain unlocked. ... it was not an issue, when I started my work as a nursing student in USA, to touch a man... there was no doubt that this was necessary (H. G.).

Beforehand, I had never touched a young man or any man. So there was a small crisis, a period of adjustment, until you realize it's just part of the job... We would talk about these things, lots of intimate conversations, but it was clear it had to be-there was no other choice. Everybody does it... And you need to know that you are doing it only as part of the job and no more... In some Orthodox circles, there are those who think that even coming near a man is unacceptable. (R. M.)

"My family supported me despite the fact that it was very rare for a religious woman to work outside the home... I was told it was a man’s world and that I would be exposed to all kinds of things” (R. T.).

\section{The Establishment of Nursing Schools Catering to Religious Women}

The establishment of nursing schools catering to religious women began in the time of Florence Nightingale, who founded the first nursing school in a Christian convent in England. Jewish women who wanted to become nurses were unable to do so. Also in Israel, the first nursing schools were affiliated with Christian convents and the studies were conducted in the Christian spirit. Only later was there a clear need for Jewish nurses, which led to the establishment of nursing schools for religious Jewish women.

The nursing school established in 1936 in affiliation with the Shaarei Tzedek Hospital in Jerusalem was the first Jewish religious nursing school in Israel. Like the hospital itself, the school operated according to Jewish religious tenets. Among the many goals that led to the establishment of the school was the desire to lessen the influence of the Christian missionary activity in the old city of Jerusalem, which at the time provided cost-free health services in an attempt to expand its Christian influence.

The curriculum at the nursing school included also religious studies, and there was a Rabbi who accompanied the program. However, at that time, Israel was under the rule of the British Mandate, and as the entire school was under British jurisdiction, there was an attempt to impose a Christian spirit on the program as well. Dr. Wallach, the first medical director of the hospital, resisted this influence, claiming that "in this country we need nurses who in addition to a strong basic education have a high level of moral standards, featuring strength and compassion, qualities that are desirable in the nursing profession, rather than nurses who seek to expand their scientific knowledge.” Furthermore, Dr. Wallach insisted that the school would conduct independent tests rather than those imposed by the health department. He claimed that each school should be allowed to conduct independent tests, especially in his school, which was one of a kind in the entire country. He 
stated that "at the heart of the matter, a student's acquired skills, responsibilities, and her chances of becoming a good nurse cannot be assessed by means of a conventional test, but rather by an ongoing evaluation over the course of the entire program.”

According to Nurse Selma,

Everyone knew just how strict and meticulous Dr. Wallach was in all things concerning the observation of the Jewish tenets at Shaarei Tzedek. The medical clinic at Shaarei Tzedek had a sign instructing male and female visitors to take a seat in separate sections. The issue of kashrut was also emphasized at the hospital. Moreover, Dr. Wallace used to walk into a study hall unannounced, just to make sure things were proceeding as required. He held careful interviews with each new nurse hired and checked her knowledge of the religious tenets. The school staff emphasized the aspect of doing good deeds and showing compassion to each patient. This type of learning, which demands that a high level of morality be maintained at all times, demonstrates the compassionate attitude of the Jewish nursing school. These characteristics were typical of a nursing school affiliated with a religious hospital. (Meir 2001)

"The religious atmosphere, the observance of Jewish tenets, modest dress and behavior... If this were not a religious hospital, my father would not have let me study at all” (R. M.). "My uncle, who was a gynecologist, said that we need religious physicians and religious nurses" (R. S.). "My family considered it more of a mission, a Mitzvah [good deed], than a profession or a way to earn a living” (N. TZ.).

The female student nurses had to sign a document agreeing to several school rules, among them agreeing not to get married in the course of their studies. Anyone who wanted to get married while attending the nursing school was either thrown out of the program, opted to leave willingly, or sought special permission from the school. (mentioned by five of the interviewees who had studied at Shaarei Tzedek)

The cornerstone for the nursing school that is now an integral part of the Laniado Hosiptal was set ten years after the construction of the hospital. As the following excerpts demonstrate, the nursing school was founded on the same basic principles that guided the establishment of the Laniado Hospital in 1976.

The mission of the Laniado Hospital reflects the vision advanced by the Hassidic leader, blessed be his memory: "the hospital will provide assistance to any person in need—not only technical assistance, but heartfelt assistance. Nurses in the hospital will be knowledgeable in their profession without forgetting the most important aspect of the nurses' work, namely, doing good, and expressing warmth, care and empathy towards the patient.” (2010)

"The educational goal of our institution is to develop the student's ability to integrate the use of professional knowledge with the overall Jewish outlook, according to which nursing is an instrument for doing the Lord's work." "Throughout the teaching process, special emphasis is placed on the sanctity of human life as the utmost value, as well as the absolutely equal right of each person to receive nursing care." "The Rabbis emphasized that in the matter of saving lives, nothing is prohibited, and doing everything [in one's power] is a duty”(2010).

In the past, the nursing school found it difficult to realize all of its principles in all fields, for example, bringing in Orthodox women lecturers, meeting all of the standards imposed by the health department, operating the school as an academic institution with credit points, and including in the curriculum subjects such as psychology, sociology, and statistics. (2010; 1983)

The pathology teacher was selected very carefully... so he would not engage the students in discussing ethical issues of surgery, or these types of topics, and the students were not taken to visit the Institute of Pathology. We try to hire mostly religious teachers... I always tried very hard to find the right kind of teachers, that is, experts who are not only religious, but who are accustomed to integrating medicine with a Jewish Orthodox way of life. (R. M.) 
The population of religious women who attend the nursing school is varied and includes single women, married women, wives of yeshiva scholars, and women who have several children. The personal attention from the staff members, who are able to take into consideration the students' family role as wife or mother, empowers students to cope with the intensive study program. In this sense, the unique character of the school enables its students to combine a religious lifestyle, meeting the demands of family life as well as those of the academic program.

The nursing department at the Tal Institute was established in 2008, to enable women to study for an academic degree in nursing within a religious environment, where the motto is "the nursing world consists entirely of charity." Hence, students attend courses not only on subjects related to medicine, but also on topics related to Jewish law. Thus, they have an opportunity to consider practical questions that arise from their work in the clinical field, for example, the issue of patient autonomy, as well as the Jewish approach to palliative and end-of-life care.

When the Tal Institute first opened I had no staff. I myself went to various hospitals in Jerusalem to find potential staff members. At first people where sceptic: "what do you mean-for a religious population? How will the students manage? Will they observe the Sabbath? Will female nurses help clean and wash male patients?” It took us two to three years to prove that we can function as well as any other nursing school, if not better. It took a lot of motivation and adhering to ideals... The Tal Institute is not affiliated with any particular hospital, which adds yet another challenge, as this makes it difficult to find suitable places where the students can gain practical experience. (H. G.)

When covering the study of mental health, we make an effort not to assign our students to a practicum in a mental health ward where male patients are admitted involuntarily. That would not be a suitable place for a religious woman, as she might find herself in religiously compromising situations. So, yes, there are things that we do differently. The students gain experience in every type of situation and ward; our aim is not to shield them from certain experiences, but to operate in line with Jewish law, and this needs to be learned. (H. G.)

The Tal Institute operates a branch at the Bnei Brak Academic College, in which ultra-Orthodox women pursue an academic degree in nursing. Before opening the branch, there were those who doubted whether women from this sector would be able to integrate professionally in the various wards. As it turns out, the premature concern was uncalled for, as the students did fit in well in all of the wards, and in some situations they were shown special consideration. Ichilov Hospital, for example, made sure to provide them with food that met the standards of kashrut practiced by the ultra-Orthodox, and they were provided with a specially-made surgical uniform consisting of a skirt rather than pants. The head of the Tal Institute, Professor Greenberger, mentioned having to scold lecturers who used indecent language unnecessarily, and in one case, she even fired a lecturer on the grounds of improper language used in class. (H. G.)

\section{Discussion and Conclusion}

The current study examined several unique factors that characterize the professional experience of Jewish religious women nurses. The literature review revealed that the notion of a religious Jewish nurse is not a phenomenon of the past few centuries, but rather has existed since the origin of the Jewish people. The Bible, which refers to midwives who helped Jewish mothers give birth, encourages doing good deeds for others. The process of giving and assisting others, which is inherent to the nursing profession, is well grounded in Judaism, as it is in Christianity.

The combination of the shortage of nurses in Israel, the establishment of religious Jewish hospitals, and the tendency of religious Jewish women to seek out good deeds provided the impetus for establishing nursing schools for religious Jewish women, where the unique challenges inherent in this juxtaposition can be addressed and successfully met. According to most of the data gathered from the interviews, it appears that the 
attitude of the Jewish religious society towards the religious Jewish nurse is a positive one, and she is viewed as taking on an important mission and performing a Mitzvah. Several of the interviewees indicated that the attitude in the ultra-Orthodox Jewish society was slightly different, such that the choice of the nursing profession was not considered appropriate and was criticized, because of the inherent contradictions between the professional requirements and the ultra-Orthodox religious way of life. The interviewees shared their experiences of coping with these contradictions and finding the golden rule that would resolve the conflict between the professional and the personal lifestyle demands. Notwithstanding these challenges, the interviewees indicated that they enjoyed their professional work, and that the overall contribution of the Jewish religious nurse is adequately recognized in the clinics and hospitals in their communities.

\section{Recommendations}

In this initial study, we examined the factors that are unique characteristics of the Jewish nurse. Our review began from the Biblical era and continued throughout history, up until the current status of the Jewish nurse in Israel. We found a paucity of information in the professional literature and hence continued to research through documents in schools, official archives, and personal diaries. The interviewees were recruited by means of personal acquaintance and through lists of nursing-school staff members. Consequently, given the paucity of official documentation, we believe that the issue should be further explored, in an attempt to locate additional resources, in order to render a broad and coherent description of the development of the nursing profession in Jewish religious communities. Topics that should be pursued include the relationship between nursing and Judaism, the attitudes and experiences of current nurses, the need for religious nurses and the cultural sensitivity towards the needs of the religious communities, as well as the attitudes and views of the secular public towards the religious Jewish nurse.

\section{Works Cited}

Bartal, N. With You All the Way: Chapters in the History of the Nursing Profession in Israel 1931-1949. Jerusalem: Carmel, 2015. Hebrew.

---. Compassion and Knowledge: Chapters in the History of the Nursing Profession in Israel 1918-1948. Jerusalem: YadItzhak Ben Tzvi, 2005. Hebrew.

Beinkovitz, P. A Letter to the Hassidic Leader. June 17, 1983. Hebrew.

Gal, B. “The Midwife among Yemenite Jews 1931-1949.” Eds. R. Adams-Stockler and R. Sharon. Landmarks in Nursing: A Compendium of Historical Studies on Nursing in Israel. Tel Aviv: Sackler Faculty of Medicine, School of Health Professions, Nursing Department, 1995. 61-80. Hebrew.

Glick, L. H. Summary of a Lecture on Basic Terminology in Nursing. Jerusalem: Lev Academic Center, Nursing Department, 2013. Hebrew.

Meir, Z. My Life in Shaarei Tzedek. Jerusalem: Shaarei Tzedek Medical Center, 2001. Hebrew.

Noibert, Y. A Halachic Guide for Hospital Nurses. Jerusalem: Beit Midrash Halakha Moriya, 1976. Hebrew.

Sharm, R. Angels among the Rocks: A Novel about the Atmosphere in the Early Days of Shaarei Tzedek Hospital. Tel Aviv: Golan, 1996. Hebrew.

Sofer, A. The Soul of Abraham. Jerusalem: Nishmat Avraham Yore Deah, Vol. 2, 2nd edition, 2007. 594-5. Hebrew.

Triya, P. “About Birth, Pregnancy and Gestation: Midwives in the Biblical Era.” Annual Journal on Biblical Ancient near East Studies 8 (2007). The Mendel Institute of Jewish Studies (Hebrew).

The Laniado School. “A Message from the Management.” Laniado Organization Website, 2010. <http://www.laniado.org.il/nursing-school.html>. 